\title{
Design of Korean Noninvasive Risk Evaluation Study for Sudden Cardiac Death from Infarction or Heart Failure - Heart failure study of K-REDEFINE registry-
}

Seung-Jung Park, MD1; Gyo-Seung Hwang, MD2; Gi-Byoung Nam, MD³; Hyung Wook Park, MD4; Joong-Wha Chung, MD5; Seung Yong Shin, MD; Sang Min Kim, MD; Jun Hyung Kim, MD; Young Soo Lee, MD ${ }^{9}$; Yae Min Park, MD10; Jong-Youn Kim, MD11; Dae Hyeok Kim, MD12; Dae kyeong Kim, MD13, June Namgung, MD ${ }^{14}$; Dae-Hee Shin, MD ${ }^{15}$; Joon Hyouk Choi, MD ${ }^{16}$; Hyoung-Seob Park, MD ${ }^{17}$; Jong-Il Choi, MD ${ }^{18}$; Jin-Seok Kim, MD ${ }^{19}$, Tae Joon Cha, MD20; Sang Weon Park, MD21; Jae-Sun Uhm, MD22; Nam-Ho Kim, MD23; Minsoo Ahn, MD24; Dong-Gu Shin, MD25; Nuri Jang ${ }^{1}$; Meemo Park ${ }^{1}$; June Soo Kim, MD1; on behalf of the K-REDEFINE investigators

\footnotetext{
'Samsung Medical Center, Sungkyunkwan University School of Medicine, Seoul, Republic of Korea; ${ }^{2}$ Ajou University Hospital, Suwon, Republic of Korea; ${ }^{3}$ Asan Medical Center, Seoul, Republic of Korea; ${ }^{4}$ Chonnam National University Hospital, Gwangju, Republic of Korea; ${ }^{5}$ Chosun university hospital, Gwangju, Republic of Korea; ${ }^{6}$ Chung-Ang University Hospital, Scoul, Republic of Korea: ${ }^{7}$ Chungbuk National University Hospital, Cheongju, Republic of Korea; ${ }^{8}$ Chungnam National University Hospital, Dacjeon, Republic of Korea; ${ }^{9}$ Dacgu Catholic University Medical Center, Daegu, Republic of Korea; ${ }^{10}$ Gachon University Gil Medical Center Incheon, Republic of Korea; ${ }^{1}$ Gangnam Severance Hospital, Seoul, Republic of Korea; ${ }^{12}$ Inha university hospital, Incheon, Republic of Korea; ${ }^{13}$ Inje University Busan Paik Hospital, Busan, Republic of Korea; ${ }^{14}$ Inje University llsan Paik Hospital, Goyang, Republic of Korea; ${ }^{15}$ International St. Mary's Hospital, Incheon, Republic of Korea; ${ }^{16}$ jeju National University Hospital, Jeju, Republic of Korea; ${ }^{17}$ Keimyung university dongsan medica center, Daegu, Republic of Korea; ${ }^{18}$ Korea University Medical Center, Seoul, Republic of Korea; ${ }^{19}$ Korea University Ansan Hospital, Ansan, Republic of Korea; ${ }^{20} \mathrm{Kosin}$ University Gospel Hospital, Busan, Republic of Korea; ${ }^{21}$ Sejong General Hospital, Bucheon, Republic of Korea; ${ }^{22}$ Severance Hospital, Yonsei University College of Medicine, Seoul, Republic of Korea ${ }^{23}$ Wonkwang University Hospital, Iksan, Republic of Korea; ${ }^{24}$ Wonju Severance Christian Hospital, Wonju, Republic of Korea; ${ }^{25}$ Yeungnam University Hospital, Dacgu, Republic of Korea
}

Received: October 19, 2016

Revision Received: November 29, 2016

Accepted: December 6, 2016

Correspondence: June Soo Kim, MD, PhD

Division of Cardiology, Department of Medicine,

Cardiac \& Vascular Center, Samsung Medical

Center, Sungkyunkwan University School of

Medicine, 81, Irwon-ro Gangnam-gu, Seoul

06351, Republic of Korea

Tel: +82-2-3410-3414, Fax: +82-2-3410-3417

Email: juneskim@skku.edu, js58.kim@samsung.com

Copyright (C) 2016 The Official Journal of Korean Heart Rhythm Society Editorial Board and MMK

Communications Limited

\section{ABSTRACT}

Background and Objectives: Sudden cardiac death (SCD) is one of the most common causes of death in patients with heart failure (HF). However, there are no available data on SCD in previous Korean HF registries. Additionally, although widely used, the utility of left ventricular (LV) ejection fraction (EF) in risk stratification for SCD is limited.

Subjects and Methods: The Korean non-invasive Risk Evaluation study for sudden cardiac DEath From INfarction or heart failurE (KREDEFINE) is the first Korean prospective, nationwide multicenter registry, primarily focused on SCD. The registry consists of 2 groups of patients presenting with (1) acute HF or (2) acute myocardial infarction (MI) at 25 tertiary referral cardiovascular centers. Using the HF-group data of the K-REDEFINE registry, the incidence and risk factors of SCD in patients with HF will be assessed. In particular, the efficacy of Holter-based ECG variables, such as T-wave alternans (marker of repolarization heterogeneity) and heart rate turbulence/ variability (maker of autonomic function), in risk stratification for SCD will be evaluated. Other cardiovascular outcomes will also be analyzed, including atrioventricular arrhythmias, HF-related admission, stroke, and overall deaths.

Conclusion and Perspective: The K-REDEFINE registry will pave the way for better management of patients with HF at high risk of SCD by elucidating the burden and risk factors of SCD and the clinical utility of various non-invasive ambulatory ECG-based parameters in risk stratification for SCD in this patient population.

Key Words: - Sudden Cardiac Death - Heart Failure -Electrocardiography - Ambulatory 


\section{Introduction}

Sudden cardiac death (SCD) is one of the leading causes of death in the US. ${ }^{1}$ Indeed, the annual incidence of SCD in the U.S. was estimated from 180,000 to $>450,000$ according to 6 relevant publications. ${ }^{2-5}$ Patients with heart failure (HF) are one of the wellknown, high-risk subgroups of SCD because about $50 \%$ of deaths in HF are caused by SCD, as shown in Western statistics. ${ }^{67}$ Moreover, the burden of HF is rapidly growing because of an ageing society and improvements in the management of patients with cardiovascular disease. ${ }^{8}$ Therefore, an enhanced understanding of SCD risk factors in HF patients has become mandatory in order to improve the outcomes of HF patients.

Left ventricular (LV) ejection fraction (EF) has been the most widely used screening tool for SCD in clinical practice. However, it was previously reported that one-third of SCD cases occurred in patients with HF with preserved EF,' and that the proportion increased to up to two-thirds of the general population. ${ }^{5}$ In addition, patients with $\mathrm{EF}$ of $<30 \%$, but without other risk factors, have a 2 -year arrhythmic death risk of $<5 \%{ }^{10}$ Therefore, continued efforts to determine another risk stratification factors are necessary. T-wave alternans (TWA) and heart rate turbulence (HRT) are non-invasive markers of cardiac electrical instability and autonomic dysfunction, respectively. Many clinical studies have demonstrated that abnormal TWA and/or HRT values are closely associated with an increased risk of SCD. ${ }^{11-14}$ However, the clinical utility of TWA and HRT has rarely been tested in Korean patients with $\mathrm{HF}$.

Therefore, our objectives are to investigate the incidence and risk factors of SCD in HF patients using a newly designed, nationwide multicenter HF registry, and to evaluate the efficacy of TWA/HRT alone or in combination with other parameters for the prediction of SCD in this patient population.

\section{Subjects and Methods}

\section{Study population}

The Korean non-invasive Risk Evaluation study for sudden cardiac DEath From INfarction or heart failurE (K-REDEFINE) is a prospective, nationwide multicenter registry consisting of 2 groups of patients presenting with (1) acute HF or (2) acute myocardial infarction (MI) at 25 tertiary referral cardiovascular centers in South Korea (Figure 1). Enrollment of patients began in November 2015 and completion is expected by the first half of 2018. After enrollment, follow-up is planned for up to 5 years for all cases.

Patients with signs or symptoms of HF and one of the following conditions such as (i) lung congestion on a chest $\mathrm{X}$-ray, (ii) bilateral rales on physical examination, or (iii) objective findings of LV systolic dysfunction or structural heart disease will be screened for eligibility to be enrolled into the acute HF group. Inclusion criteria for the HF group are as follows: (1) patients admitted for new-onset acute HF or acute decompensation of chronic HF, (2) adult patients, $\geq 19$ years, and (3) patients with sinus rhythm (SR). Exclusion criteria include (1) persistent/ permanent atrial fibrillation (AF), (2) ventricular paced rhythm, (3) life-threatening co-morbidity with life expectancy $<1$ year, (4) end stage renal disease requiring renal replacement therapy, or (5) inability or unwillingness to give consent. The patients will be categorized as either de novo (new-onset) acute HF or acute

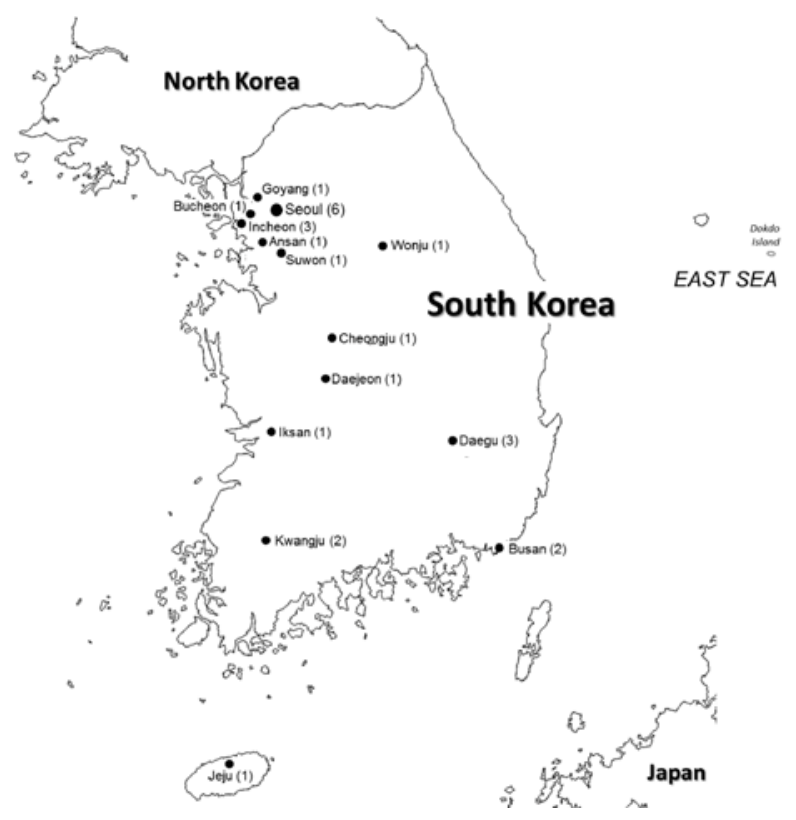

Figure 1. Participating centers in the K-REDEFINE registry The K-REDEFINE registry is the first prospective, nationwide, multicenter registry, primarily focused on sudden cardiac death in patients with acute heart failure and myocardial infarction. The location and the number of the participating centers in each location are marked in the map. 
Table 1. Details of baseline data in heart failure study

\begin{tabular}{|c|}
\hline Demographics \\
\hline Age \\
\hline Sex \\
\hline Height/ Weight/ Body mass index \\
\hline Body surface area \\
\hline Symptom at Admission \\
\hline Dyspnea with NYHA functional class \\
\hline Palpitation \\
\hline (Pre) syncope \\
\hline Medical History \\
\hline Heart failure \\
\hline Hypertension \\
\hline Diabetes \\
\hline Smoking \\
\hline Myocardial infarction \\
\hline Previous $\mathrm{PCl}$ or $\mathrm{CABG}$ \\
\hline Previous valvular surgery \\
\hline Peripheral artery disease \\
\hline Aortic plaque \\
\hline Paroxysmal atrial fibrillation \\
\hline Stroke/TIA/systemic embolism \\
\hline $\mathrm{CHA}_{2} \mathrm{DS}_{2}-\mathrm{VASc}$ score* \\
\hline Chronic obstructive pulmonary disease \\
\hline Chronic kidney disease \\
\hline Family history of sudden cardiac death \\
\hline Previous history of sudden cardiac arrest \\
\hline Laboratory test \\
\hline Hemoglobin \\
\hline Total/HDL/LDL cholesterol \\
\hline Blood urea nitrogen \\
\hline Creatinine \\
\hline Creatinine clearance \\
\hline Serum sodium \\
\hline Serum potassium \\
\hline High-sensitivity C-reactive protein \\
\hline N-terminal prohormone of brain natriuretic peptide \\
\hline Echocardiographic parameters \\
\hline Left ventricular end diastolic diameter \\
\hline Left ventricular end systolic diameter \\
\hline Left ventricular ejection fraction \\
\hline Left ventricular end diastolic volume \\
\hline Left ventricular end systolic volume \\
\hline Left atrial diameter \\
\hline Left atrial volume index \\
\hline
\end{tabular}

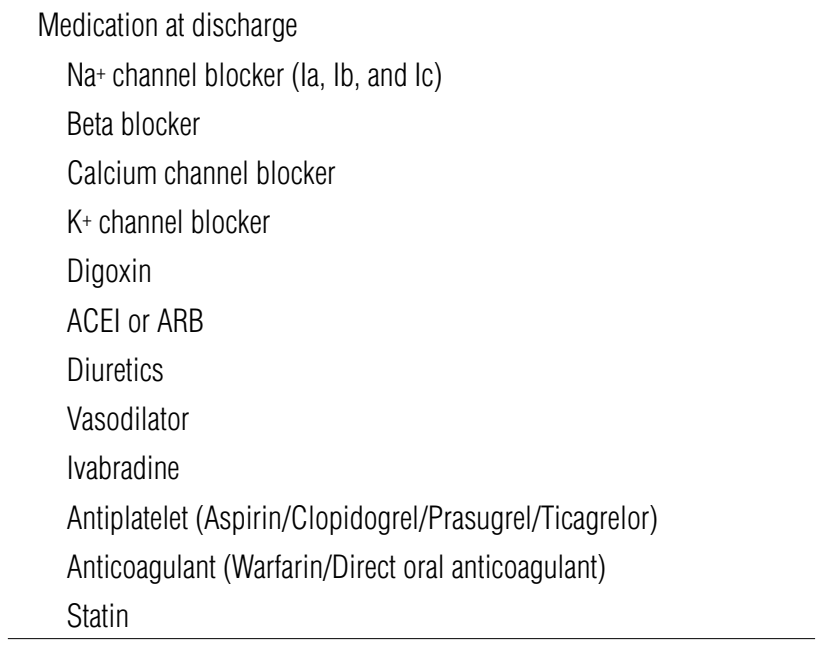

ACEl, angiotensin-converting enzyme inhibitor; ARB, angiotensin II receptor blocker; CABG, coronary artery bypass graft surgery; HDL, high density lipoprotein; LDL, low density lipoprotein; NYHA, New York Heart Association; $\mathrm{PCl}$, percutaneous coronary intervention; TIA, transient ischemic attack.

${ }^{*} \mathrm{CHA}_{2} \mathrm{DS}_{2}$-VASc score (congestive heart failure, hypertension, age $\geq 75$ years [doubled], diabetes, stroke/transient ischemic attack/thromboembolism [doubled], vascular disease [prior myocardial infarction, peripheral artery disease, or aortic plaque], age 65-75 years, sex category [female])

decompensation of chronic HF by the attending physician. Classification of ischemic versus non-ischemic cardiomyopathy will be performed and the etiologies of non-ischemic cardiomyopathy will be determined during the index admission from among the following: valvular heart disease, congenital heart disease, cardiomyopathy, hypertensive HF, acute myocarditis, infiltrative disease, tachycardia-induced cardiomyopathy, thyroid disease-related HF, or toxic agent (chemotherapy) related HF.

Since no previous registry has specifically addressed the issue of SCD in Korean HF or MI patients, we chose to place no limitation on the sample size of the present study. Therefore, sample size was estimated based on the number of patients enrolled in previous registries of the Korean population ${ }^{15-18} ; 1000$ consecutive patients will be enrolled for each acute HF and acute MI group, respectively, resulting in a total of 2000 patients.

Written, informed consent will be obtained from all enrolled patients. If patients are unable to give consent by themselves due to certain disabilities, obtaining an informed consent from legal representatives will be allowed. The study has been approved by the local institutional review board of each participating center. 
Table 2. Details of settings for TWA and HRT measurement

Standardized Settings for TWA analysis

Update factor of $1 / 8$

Noise limit of $20 \mu \mathrm{V}$

Heart rate limit of 120 beats/min

Amplitude resolution of $5 \mu \mathrm{V}$

Characteristics of suitable VPC for HRT analysis

VPC with prematurity $>20 \%$ of the reference RR interval ${ }^{\star}$

VPC with a compensatory pause of $>120 \%$ of the reference RR interval ${ }^{*}$

VPC with 2 normal RR intervals prior to the VPC

VPC with 15 normal RR intervals after the VPC

Filter settings used to reject unsuitable rhythm strips for HRT analysis

Very short RR intervals (<200 msec.) prior to or after VPCs

Very long RR intervals (>2000 msec.) prior to or after VPCs

RR intervals with substantial difference (>200 ms) to the preceding sinus interval

RR intervals with substantial difference $(>20 \%)$ to the reference RR interval*

HRT, heart rate turbulence; TWA, T-wave alternans; VPC, ventricular premature contraction

${ }^{*}$ Reference RR interval = mean of the 5 last sinus RR intervals preceding the VPC

\section{Study protocol and data collection}

The study is funded by a grant by the Korean Heart Rhythm Society, and the study protocol and case report forms have been designed by the Non-Invasive Study Steering Committee of the Korean Heart Rhythm Society. Data collection will be prospectively performed by attending physicians using a webbased electronic case report form at each participating center with the aid of a clinical research coordinator. Direct participant identifiers such as names, personal numbers, and medical record numbers will be replaced by linking codes. Specific baseline demographics, clinical characteristics, 12-lead ECG and Holterbased variables including TWA and HRT values, echocardiographic parameters, laboratory results, and medications will be obtained at the index admission. Details of the baseline clinical data that will be collected are shown in Table 1 .
Measurement of TWA and HRT using ambulatory ECG recording

Ambulatory electrocardiograms will be recorded during the index admission prior to discharge or within three months after discharge using an ambulatory 3-lead SEER Light Digital Holter monitor with a sampling rate of 125 samples per second (GE Healthcare Inc. Milwaukee, WI, USA). All of the participating centers will be encouraged to record Holter ECG data for at least 20 hours in order to incorporate overall circadian variation in the TWA and HRT levels during daytime and nighttime. Additionally, a careful skin preparation will be performed to obtain a high quality signal and to minimize noise. ${ }^{12}$ Raw ambulatory ECG data recorded at each center will be collected and sent to the core laboratory (Samsung Medical Center) to be analyzed under standardized analysis settings, the details of which 
Table 3. Surface and ambulatory ECG-related variables

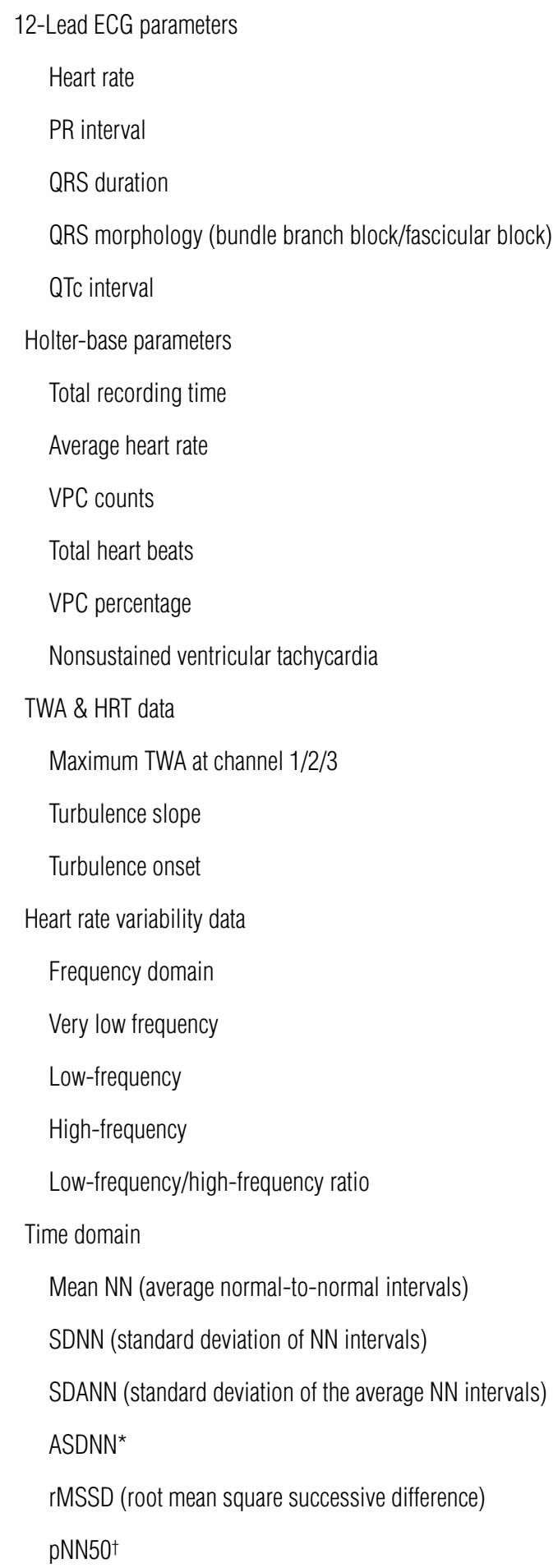

ECG, electrocardiography; HRT, heart rate turbulence; NN, normal-to-normal RR interval; TWA, T-wave alternans; VPC, ventricular premature contraction *Standard deviation of the average of NN intervals in all 5-minute segments of a 24-h recording tPercentage of differences between adjacent NN intervals that are $>50 \mathrm{msec}$; this is one member of the larger pNNx family are provided in Table 2. TWA and HRT values will be analyzed using a MARS 8000 Holter analyzer (GE Healthcare Inc., Milwaukee, WI, USA). The TWA value is to be measured in 3 precordial leads $\left(V_{1}, V_{3}\right.$, and $\left.V_{5}\right)$ using the modified moving average method (MMA) based on the time-domain algorithm of TWA. ${ }^{1113}$ The MMA method enables a quantitative assessment of TWA level in contrast to the conventional spectral method, which gives only qualitative results. ${ }^{11}$ TWA measures will undergo review and confirmation processes by 2 dedicated cardiologists with the assistance of 1 ECG specialist. Thereafter, the maximum TWA value obtained in a corresponding ECG rhythm strip without noise or artifacts will be ultimately accepted. For the HRT assessment, 2 quantitative values will be measured: The turbulence onset (TO) and turbulence slope (TS). Values of TO $>0 \%$ and $\mathrm{TS}<2.5 \mathrm{~ms} / \mathrm{RR}$ interval will be defined as abnormal, as in previous studies. ${ }^{12}$ HRT will be defined as abnormal when either TO or TS shows abnormal values. In addition, patients will be classified into 3 groups as follows: HRT0 (both TO and TS normal), HRT1 (either TO or TS abnormal), and HRT2 (both TO and TS abnormal). Apart from the TWA and HRT measurements, several Holter-based variables will also be obtained using the same time- and frequency-domain HR variability (HRV) parameters. Details of the Holter-based variables analyzed in the present study are presented in Table 3.

\section{Discharge information and clinical outcomes during follow-up}

Standardized report forms will be used to collect information at discharge and at the time of follow-up events. Discharge information will include survival status, type of death (noncardiac, non-sudden cardiac, or SCD) if occurred, type of cardiac device therapy (pacemaker, defibrillator, or biventricular pacemaker) if employed, and duration of hospitalization. Followup information will be gathered 1, 3, 6, and 12 months after discharge and annually thereafter for up to 5 years. The primary end point is SCD, which is defined as unexpected death due to cardiac causes that occurs within a short time period (within 1 hour of symptom onset or un-witnessed death during sleep). ${ }^{2}$ Other primary and secondary outcomes are shown in Table 4. All clinical events such as death and re-hospitalization will undergo 
Table 4. Study end points

Primary end points
Sudden cardiac death
Ventricular fibrillation
Sustained ventricular tachycardia
Appropriate ICD discharge or Anti-tachycardia therapy
Secondary end points
All cause death
Cardiac death
New-onset atrial fibrillation
Transient ischemic event, stroke, or systemic embolism
Heart failure-related rehospitalization
Myocardial infarction
Coronary revascularization (PCI or CABG)

CABG, coronary artery bypass graft surgery; ICD, implantable cardioverterdefibrillator; PCl, percutaneous coronary intervention

verification from an independent Clinical Event Adjudication Committee, which consists of experts in HF and MI. The survival status and outcome data for subjects lost to follow-up will be supplemented by a telephone interview in which a structured questionnaire will be used by all participating centers.

\section{Discussion}

\section{Burden of sudden cardiac death in Korea}

SCD is among the most common causes of death in Western countries, and the rates of SCD in Korea are reportedly comparable. ${ }^{19}$ The annual incidence of SCD in Korea was more than 41 per 100,000 people according to a recent study performed as a complete enumeration survey using the 2-year (2006 to 2007) emergency medical service (EMS) medical records pertaining to out-of-hospital SCD. In 2006 and 2007, 20,000 persons experienced out-of-hospital sudden cardiac arrest and similar incidences are seen in other developed countries such as the U.S.A., Canada, Ireland, and Japan. Moreover, the estimated incidence would have been even greater if the in-hospital SCD cases had also been incorporated into the survey.

\section{Need for the K-REDEFINE registry}

SCD accounts for a potentially significant portion of all causes of death in Korean HF patients, similarly to other developed countries, due to the increased prevalence of westernized lifestyle factors in many Asian countries including Korea. Despite the clinical importance of SCD in the HF population, there has been no data regarding this issue in Korea. Although several welldesigned multicenter HF registries have been established in Korea, they do not provide sufficient data associated with SCD specifically. ${ }^{15,16}$ For example, the Korean Heart Failure (KorHF) Registry, a nationwide, multicenter registry of 3,200 consecutive patients with acute $\mathrm{HF}$, has provided us ample valuable insights on many aspects of HF management. Another prospective multicenter registry, the Korean Acute Heart Failure (KorAHF) registry, is currently ongoing with the expectation that regionspecific registries facilitate a better understanding of each region's own HF patients. However, the KorHF and KorAHF registries are not collecting data pertaining to $S C D$, and information on anti-arrhythmic medications, the use of cardiac implantable electronic device (CIED), ventricular arrhythmic events, and aborted SCD is also lacking.

Thus, this lack of data on SCD in HF in Korea might be closely related to underutilization of potentially life-saving therapies such as implantable cardioverter-defibrillator (ICD) or cardiac resynchronization therapy (CRT) devices. In fact, the rate of ICD or CRT implantation was only $1.3 \%$ in a sub-study of the KorHF registry. ${ }^{20}$ In addition, according to the 11th world survey of cardiac pacing and ICD, the annual rate of new ICD or CRTdefibrillator (CRT-D) implantation in Korea was much lower than that in Japan or the U.S.A., even if corrected by population. In 2009, 42 and 434 patients per million of the population received ICD/CRT-D implantation in Japan and the U.S.A., respectively. In contrast, only 6 cases per million were performed in Korea during that same year. ${ }^{21}$

Therefore, given this situation, this registry will provide clinicians with valuable assistance in the identification of SCD 
predictors, and in the adequate and timely allocation of potentially life-saving therapies to the high-risk HF subgroup.

\section{TWA and HRT for SCD}

In the K-REDEFINE study, various non-invasive parameters will be assessed prospectively such as TWA, HRT, HRV, 12-lead ECG-based data, and echocardiographic variables. TWA refers to beat-to-beat oscillation in the shape and amplitude of the ST-segment and/or T-wave. Several in vitro and in vivo experiments proved that the temporo-spatial heterogeneity of repolarization is closely associated with this phenomenon of TWA, ${ }^{11}$ and its magnitude was well correlated with the risk of arrhythmogenesis.2-24 Enhanced adrenergic activity and abnormal intracellular calcium handling in HF may lead to augmented inhomogeneity of repolarization, ${ }^{25}$ which in turn may be manifested by an increased TWA level and elevated risk of lethal arrhythmia.

HRT represents a biphasic change of the sinus RR interval following ventricular premature contractions (VPCs), with an initial decrease followed by a subsequent increase. ${ }^{12}$ The initial decrease is caused by transient vagal withdrawal following a VPCinduced reduction in blood pressure (BP), whereas the subsequent increase is related to baroreflex-mediated transient $\mathrm{BP}$ elevation. Therefore, HRT assessment is an indirect evaluation of baroreflex function and patients with HF frequently show blunted HRT. ${ }^{12,24,26}$

TWA and HRT have already been investigated, although in most of the studies, TWA was assessed mainly in post-MI patients and merely qualitatively using the spectral method. ${ }^{23,24}$ Thus, the K-REDEFINE study will represent one of the largest cohorts to evaluate the association between TWA/HRT and SCD in patients with HF using ambulatory ECG data. Previous data shows contradictory results regarding abnormal HRT values in the prediction of SCD in patients with $\mathrm{HF}^{26,27}$ Therefore, the K-REDEFINE study, in which TWA will be measured quantitatively using the MMA method, might promote our understanding of the role of TWA and HRT in identifying patients with $\mathrm{HF}$ at high risk of SCD.

\section{Conclusion}

The HF study of the K-REDEFINE registry is the first Korean prospective study primarily focused on SCD in HF patients from 25 centers in Korea. The K-REDEFINE registry will pave the way for the superior management of patients with $\mathrm{HF}$ who are at high risk of SCD by elucidating the burden and risk factors of SCD, as well as the clinical utility of various non-invasive ambulatory ECG-based parameters in risk stratification for SCD in this patient population.

\section{Acknowledgements}

The present study is supported by The Korean Heart Rhythm Society. We express our sincere gratitude to the investigators at the 25 participating university hospitals and medical centers for their contributions to this study, and to GE Healthcare Korea for their support for the establishment of the web-based electronic case report form. Additionally, we would like to clarify that GE Health Korea has no access to patient-related data. Participating centers are as follows in alphabetical order: Ajou University Hospital, Asan Medical Center, Chonnam National University Hospital, Chosun University Hospital, Chung-Ang University Hospital, Chungbuk National University Hospital, Chungnam National University Hospital, Daegu Catholic University Medical Center, Gachon University Gil Medical Center, Inha University Hospital, Inje University Busan Paik Hospital, Inje University Ilsan Paik Hospital, International St. Mary's Hospital, Jeju National University Hospital, Keimyung University Dongsan Medical Center, Korea University Medical Center, Korea University Ansan Hospital, Kosin University Gospel Hospital, Samsung Medical Center, Sejong General Hospital, Severance Hospital of Yonsei University College of Medicine, Wonkwang University Hospital, Wonju Severance Christian Hospital, and Yeungnam University Hospital.

\section{References}

1) Kong MH, Fonarow GC, Peterson ED, Curtis AB, Hernandez AF, Sanders GD, Thomas KL, Hayes DL, Al-Khatib SM. Systematic review of the incidence of sudden cardiac death in the United States. J Am Coll Cardiol. 2011;57: 794-801.

2) Chugh SS, Jui J, Gunson K, Stecker EC, John BT, Thompson B, 
Ilias N, Vickers C, Dogra V, Daya M, Kron J, Zheng ZJ, Mensah G, McAnulty J. Current burden of sudden cardiac death: multiple source surveillance versus retrospective death certificate-based review in a large U.S. community. J Am Coll Cardiol. 2004;44:1268-1275.

3) Zheng ZJ, Croft JB, Giles WH, Mensah GA. Sudden cardiac death in the United States, 1989 to 1998. Circulation. 2001;104:21582163.

4) Nichol G, Thomas E, Callaway CW, Hedges J, Powell JL, Aufderheide TP, Rea T, Lowe R, Brown T, Dreyer J, Davis D, Idris A, Stiell I; Resuscitation Outcomes Consortium Investigators. Regional variation in out-of-hospital cardiac arrest incidence and outcome. JAMA. 2008;300:1423-1431.

5) Chugh SS, Reinier K, Teodorescu C, Evanado A, Kehr E, Al Samara M, Mariani R, Gunson K, Jui J. Epidemiology of sudden cardiac death: clinical and research implications. Prog Cardiovasc Dis. 2008;51:213-228.

6) McMurray JJ, Adamopoulos S, Anker SD, Auricchio A, Böhm M, Dickstein K, Falk V, Filippatos G, Fonseca C, Gomez-Sanchez MA, Jaarsma T, Køber L, Lip GY, Maggioni AP, Parkhomenko A, Pieske BM, Popescu BA, Rønnevik PK, Rutten FH, Schwitter J, Seferovic P, Stepinska J, Trindade PT, Voors AA, Zannad F, Zeiher A; Task Force for the Diagnosis and Treatment of Acute and Chronic Heart Failure 2012 of the European Society of Cardiology, Bax JJ, Baumgartner H, Ceconi C, Dean V, Deaton C, Fagard R, FunckBrentano C, Hasdai D, Hoes A, Kirchhof P, Knuuti J, Kolh P, McDonagh T, Moulin C, Popescu BA, Reiner Z, Sechtem U, Sirnes PA, Tendera M, Torbicki A, Vahanian A, Windecker S, McDonagh T, Sechtem U, Bonet LA, Avraamides P, Ben Lamin HA, Brignole M, Coca A, Cowburn P, Dargie H, Elliott P, Flachskampf FA, Guida GF, Hardman S, Iung B, Merkely B, Mueller C, Nanas JN, Nielsen OW, Orn S, Parissis JT, Ponikowski P; ESC Committee for Practice Guidelines. ESC guidelines for the diagnosis and treatment of acute and chronic heart failure 2012: The task force for the diagnosis and treatment of acute and chronic heart failure 2012 of the European Society of Cardiology. Developed in collaboration with the Heart Failure Association (HFA) of the ESC. Eur J Heart Fail. 2012;14:803-869.

7) Zipes DP, Camm AJ, Borggrefe M, Buxton AE, Chaitman B, Fromer M, Gregoratos G, Klein G, Moss AJ, Myerburg RJ, Priori SG, Quinones MA, Roden DM, Silka MJ, Tracy C, Priori SG, Blanc JJ, Budaj A, Camm AJ, Dean V, Deckers JW, Despres C, Dickstein K, Lekakis J, McGregor K, Metra M, Morais J, Osterspey
A, Tamargo JL, Zamorano JL, Smith SC Jr, Jacobs AK, Adams CD, Antman EM, Anderson JL, Hunt SA, Halperin JL, Nishimura R, Ornato JP, Page RL, Riegel B; American College of Cardiology; American Heart Association Task Force; European Society of Cardiology Committee for Practice Guidelines; European Heart Rhythm Association; Heart Rhythm Society. ACC/AHA/ESC 2006 guidelines for management of patients with ventricular arrhythmias and the prevention of sudden cardiac death: a report of the American College of Cardiology/American Heart Association task force and the European Society of Cardiology Committee for practice guidelines (Writing Committee to Develop guidelines for management of patients with ventricular arrhythmias and the prevention of sudden cardiac death) developed in collaboration with the European Heart Rhythm Association and the Heart Rhythm Society. Europace. 2006;8:746-837.

8) Sanderson JE, Mayosi B, Yusuf S, Reddy S, Hu S, Chen Z, Timmis A. Global burden of cardiovascular disease. Heart. 2007;93:1175.

9) Hamaguchi S, Kinugawa S, Sobirin MA, Goto D, TsuchihashiMakaya M, Yamada S, Yokoshiki H, Tsutsui H; JCARE-CARD Investigators. Mode of death in patients with heart failure and reduced vs. preserved ejection fraction: report from the registry of hospitalized heart failure patients. Circ J. 2012;76:1662-1669.

10) Buxton AE, Lee KL, Hafley GE, Pires LA, Fisher JD, Gold MR, Josephson ME, Lehmann MH, Prystowsky EN; MUSTT Investigators. Limitations of ejection fraction for prediction of sudden death risk in patients with coronary artery disease: lessons from the MUSTT study. J Am Coll Cardiol. 2007;50:1150-1157.

11) Verrier RL, Klingenheben T, Malik M, El-Sherif N, Exner DV, Hohnloser SH, Ikeda T, Martínez JP, Narayan SM, Nieminen T, Rosenbaum DS. Microvolt T-wave alternans physiological basis, methods of measurement, and clinical utility--consensus guideline by International Society for Holter and Noninvasive Electrocardiology. J Am Coll Cardiol. 2011;58:1309-1324.

12) Bauer A, Malik M, Schmidt G, Barthel P, Bonnemeier H, Cygankiewicz I, Guzik P, Lombardi F, Müller A, Oto A, Schneider R, Watanabe M, Wichterle D, Zareba W. Heart rate turbulence: standards of measurement, physiological interpretation, and clinical use: International Society for Holter and noninvasive electrophysiology consensus. J Am Coll Cardiol. 2008;52:13531365.

13) Hoshida K, Miwa Y, Miyakoshi M, Tsukada T, Yusu S, Yoshino H, Ikeda T. Simultaneous assessment of T-wave alternans and heart rate turbulence on holter electrocardiograms as predictors for 
serious cardiac events in patients after myocardial infarction. Circ J. 2013;77:432-438.

14) Libbus I, Nearing BD, Amurthur B, KenKnight BH, Verrier RL. Autonomic regulation therapy suppresses quantitative $\mathrm{T}$-wave alternans and improves baroreflex sensitivity in patients with heart failure enrolled in the ANTHEM-HF study. Heart Rhythm. 2016;13:721-728.

15) Choi DJ, Han S, Jeon ES, Cho MC, Kim JJ, Yoo BS, Shin MS, Seong IW, Ahn Y, Kang SM, Kim YJ, Kim HS, Chae SC, Oh BH, Lee MM, Ryu KH; KorHF Registry. Characteristics, outcomes and predictors of long-term mortality for patients hospitalized for acute heart failure: a report from the Korean Heart Failure Registry. Korean Circ J.2011;41:363-371.

16) Lee SE, Cho HJ, Lee HY, Yang HM, Choi JO, Jeon ES, Kim MS, Kim JJ, Hwang KK, Chae SC, Seo SM, Baek SH, Kang SM, Oh IY, Choi DJ, Yoo BS, Ahn Y, Park HY, Cho MC, Oh BH. A multicentre cohort study of acute heart failure syndromes in Korea: rationale, design, and interim observations of the Korean Acute Heart Failure (KorAHF) registry. Eur J Heart Fail. 2014;16:700-708.

17) Song YB, Hahn JY, Kim JH, Lee SY, Choi SH, Choi JH, Choi SH, Lee SH, Yoon J, Kim YJ, Jeong MH, Gwon HC; Korea Acute Myocardial Infarction Registry Investigators. Comparison of angiographic and other findings and mortality in non-ST-segment elevation versus ST-segment elevation myocardial infarction in patients undergoing early invasive intervention. Am J Cardiol. 2010;106:1397-1403.

18) Park HW, Yoon CH, Kang SH, Choi DJ, Kim HS, Cho MC, Kim YJ, Chae SC, Yoon JH, Gwon HC, Ahn YK, Jeong MH; KAMIR/KorMI Registry. Early- and late-term clinical outcome and their predictors in patients with ST-segment elevation myocardial infarction and non-ST-segment elevation myocardial infarction. Int J Cardiol. 2013;169:254-261.

19) Dong-Jin Oh. Overview of sudden cardiac death in Korea (Outof-hospital cardiac arrest). Int J Arrhythm. 2010;11:13-16.

20) Park SJ, On YK, Byeon K, Kim JS, Choi JO, Choi DJ, Ryu KH, Jeon ES. Short- and long-term outcomes depending on electrical dyssynchrony markers in patients presenting with acute heart failure: clinical implication of the first-degree atrioventricular block and QRS prolongation from the Korean Heart Failure registry. Am Heart J. 2013;165:57-64.e2.

21) Mond HG, Proclemer A. The 11th world survey of cardiac pacing and implantable cardioverter-defibrillators: calendar year 2009--a World Society of Arrhythmia's project. Pacing Clin Electrophysiol. 2011;34:1013-1027.

22) Chow T, Kereiakes DJ, Bartone C, Booth T, Schloss EJ, Waller T, Chung E, Menon S, Nallamothu BK, Chan PS. Microvolt T-wave alternans identifies patients with ischemic cardiomyopathy who benefit from implantable cardioverter-defibrillator therapy. J Am Coll Cardiol. 2007;49:50-58.

23) Ikeda T, Yoshino H, Sugi K, Tanno K, Shimizu H, Watanabe J, Kasamaki Y, Yoshida A, Kato T. Predictive value of microvolt T-wave alternans for sudden cardiac death in patients with preserved cardiac function after acute myocardial infarction: results of a collaborative cohort study. J Am Coll Cardiol. 2006; $48: 2268-2274$.

24) Exner DV, Kavanagh KM, Slawnych MP, Mitchell LB, Ramadan D, Aggarwal SG, Noullett C, Van Schaik A, Mitchell RT, Shibata MA, Gulamhussein S, McMeekin J, Tymchak W, Schnell G, Gillis AM, Sheldon RS, Fick GH, Duff HJ; REFINE Investigators. Noninvasive risk assessment early after a myocardial infarction the REFINE study. J Am Coll Cardiol. 2007;50:2275-2284.

25) Wilson LD, Jeyaraj D, Wan X, Hoeker GS, Said TH, Gittinger M, Laurita KR, Rosenbaum DS. Heart failure enhances susceptibility to arrhythmogenic cardiac alternans. Heart Rhythm. 2009;6:251259.

26) Barthel P, Schneider R, Bauer A, Ulm K, Schmitt C, Schömig A, Schmidt G. Risk stratification after acute myocardial infarction by heart rate turbulence. Circulation. 2003;108:1221-1226.

27) Grimm W, Schmidt G, Maisch B, Sharkova J, Muller HH, Christ M. Prognostic significance of heart rate turbulence following ventricular premature beats in patients with idiopathic dilated cardiomyopathy. J Cardiovasc Electrophysiol. 2003;14:819-824. 